\title{
Dr. CHEADLE AND INFANTILE SCURVY
}

\author{
BY \\ F. JOHN POYNTON, M.D., F.R.C.P., \\ Consulting Physician, Hospital for Sick Children, Great Ormond Street.
}

The writer of this short article has always felt a certain glamour surrounding the lives of the distinguished physicians and surgeons of former days. This becomes less evident among those of our own day possibly because times have greatly changed and possibly because one has grown up alongside them. There is a thrill in the vision of Dr. Fordyce in 1784 working away feverishly in the Honourable Artillery Ground superintending the inflation of Lunardi's balloon with inflammable gas on the occasion of the first aerial journey in this country, doing this in the presence of a crowd of 150,000 spectators crammed into this space and ready enough to be truculent. Dr. Cheadle had around him much of this glamour. A large powerful Yorkshireman of immense tenacity of purpose had he not made the famous North-West Passage by land across Canada with Lord Milton? Many a time the writer, who had the honour of living with him for ten years and standing by him in days of sorrow and suffering, has seen the belt which he had pulled in inch by inch whilst starving on that perilous and famous journey.

Cheadle had seen the splendid and undebased Red Indian and had given a name to a mountain which was later described by Grant in 'Ocean to Ocean' as the 'biceps Parnassus' and Grant named his camp pitched near by this mountain ' Cheadle Camp.' His journey of exploration began on the screw steamer Anglo-Saxon bound from Liverpool to Quebec on June 19, 1862, and on July 2 they steamed up the St. Lawrence to Quebec and thence made their way from the Atlantic to the Pacific. Their intention was to explore a route across Canada through British territory by one of the northern passes in the Rocky Mountains to British Columbia. This journey was described by the explorers in 'The North-West Passage by Land,' the ninth edition of which was published in 1901 . 
This part of Cheadle's life is alluded to because he told me that in those wanderings he learnt much about adult scurvy, smallpox, starvation, massacres and hair-breadth adventures. He often told me also that when he returned to London and was on the honorary staff of the Hospital for Sick Children, Great Ormond Street, he recognized the scurvy of infants, and that he had known doctors clip the fungating gums of these children in sheer perplexity as to know how to act. Also he impressed upon me the anti-scorbutic principle of his treatment of these cases, insisting that it was a special and not a general alteration in the diet.

It was Cheadle who wrote 'The Rheumatic State in Children' in which he recorded facts which are almost daily being rediscovered. Yet his contribution to the knowledge of infantile scurvy must I think be the greatest monument to his memory. Charming with patients, he would place his great hand on a child in a way which almost seemed to obliterate the patient, yet that child would call after him 'Doctor Cheagle, doctor Cheagle, I want a sweet': but no man was more difficult to know for he was both shy and reserved.

It was with this sense of glamour that one reads the opening sentence of his famous clinical lecture on 'Three cases of scurvy supervening on rickets in young children' published in 'The Lancet' in the second volume of 1878. He writes: 'The outbreak of scurvy during the late Polar Expedition on which it had so disastrous an influence, has specially associated the disease in the public mind with an Arctic climate.' In those days naval officers still attributed scurvy to extreme cold, prolonged absence of sunlight and severe physical exertion rather than to diet. Cheadle then points out that it occurs in tropical climates and under the full glare of a summer's sun, and proceeds to describe three cases of scurvy in young children of ages from sixteen months to three years. These, he says, had no protracted exposure to great cold, or prolonged absence of sunlight, or again exhausting physical exertion, but they had been strangely dieted. The first child from the sixth to the fourteenth month was not given any milk or meat or potatoes and nothing but oatmeal, rusks and water with a little mutton broth. The second from the thirteenth to the sixteenth month had lived on bread with a little butter and a one-seventh share in a pint of milk together with a patent food. The third had been weaned at two years and then fed for about a year upon bread and butter and tea with occasionally some German sausage and a little brandy and water.

These three cases were examples of rickets and scurvy combined, but of scurvy of such severity that of one case Cheadle writes ' dark red, soft and gelatinous masses protruded from the mouth between the lips and gave the 
child the appearance of being engaged in sucking pieces of raw flesh.' After the classical descriptions of the case, which illustrated also the varied though unsuccessful efforts at treatment attempted by doctors who were groping in darkness for the cause, Cheadle writes 'the diet was, however, more than a rickety diet it was a scurvy diet.' The word scurvy is in italics. This sentence of his is an historic one in English medicine.

Thinking as it were in print over this infantile scurvy he asks why did these three rickety children out of all the number alone become scorbutic? 'All the number' refers to the rickets which was then so frequent. I believe, he then answers himself, one factor was wanting in all these three casespotatoes, and he points out that in those days after a child was weaned the poor could not afford meat, but gave the children potatoes and gravy and Dr. Baly had already shown that potatoes were strongly anti-scorbutic or, if this article is to be tinged with modernity, were rich in vitamin $\mathbf{C}$.

Let me rescue from the forest of well-meant but ineffectual methods of treatment one example from the three cases which shows what Cheadle did. His treatment consisted in a full allowance of unboiled milk with mashed potatoes beaten up in milk, raw meat and the juice of two oranges. He gives the description of the recoveries with no boastfulness but as simple records of facts. They were then indeed marvellous recoveries.

This paper, written in 1878 , is fine both in its sagacity and simplicity. The children can be seen together with the perplexities, and in simple words the treatment and its results are expressed. It is surprising that there are not found in 'The Lancet' letters and further experiences confirming and praising this masterly article. When we remember the infantile scurvy we saw some thirty years ago coinciding with the influx of patent foods we cannot but read that short paper with reverence and thankfulness.

Cheadle was essentially a clinician. Though busy in practice he would never make appointments in his hospital hours. He would never let his house-physician have a day away from hospital if there was a patient dangerously ill. 'Do not leave a dying man' was his stern command. If fate had been unkind, England might never have had this famous man, for he was to have rowed but for illness in the Cambridge boat that sank in the University race and he could not swim! He was indeed a man of iron, for when nearly seventy years of age he would stay up night after night looking after his beloved wife, then snatch a little sleep after breakfast and work away through the day, sleeping again toward evening before dinner while I kept watch for him. 
I have been fortunate in my teachers, but there is one honour I greatly prize: it is that in the well-known 'System of Medicine' by Allbutt and Rolleston, Cheadle coupled my name with his in the article upon infantile scurvy and it is interesting to relate that the radiographic picture in that article was taken from a case over which I had gone astray to be corrected by Sir Thomas Barlow. No doctor young or old can read that paper of Cheadle's written in 1878 and not see in it one of the classics of English medicine. 